\title{
Educação Ambiental como Centralidade na Formação de Gestores Ambientais municipais em fronteira marítima
}

\author{
Educación Ambiental como Centralidad en la Formación de Gestores \\ Ambientales municipales en frontera marítima
Environmental Education as Centrality in the Formation of municipal Environmental Managers in maritime border

\author{
Alex Nunes Molina ${ }^{1}$ \\ Darlene Silveira Cabrera ${ }^{2}$ \\ Luis Fernando Minasi ${ }^{3}$
}

\begin{abstract}
Resumo
Este artigo se efetiva como resultado parcial de pesquisa de mestrado, através do Programa de Pós-Graduação em Educação Ambiental da Universidade Federal do Rio Grande (FURG), almejando compreender que Formação de Educadores(as) Ambientais se desenvolve no Convênio 069/2015 pela FURG junto à Prefeitura Municipal do Rio Grande no contexto do Licenciamento Ambiental. Para tal, vislumbramos este convênio como centralidade compreendendo a relevância para o vir a ser da Educação Ambiental que deve contemplar Programas de Educação Ambiental, para entendimento da realidade social da Classe Trabalhadora em regiões Fronteira Marítima, exigidos nos licenciamentos municipais pelos(as) Gestores(as), os quais consideramos Educadores(as) Ambientais. Assim, essa pesquisa se desenvolve pelo referencial teórico histórico, dialético e materialista, conduzido através de uma Abordagem Qualitativa (TRIVIÑOS, 1987), valendo-se da Análise de Conteúdo (BARDIN, 1977) para sistematização e interpretação das informações coletadas na conjuntura material do fenômeno de pesquisa. Dessa forma, como resultados parciais dessa pesquisa - a partir da análise das Políticas Nacionais Meio Ambiente e Educação Ambiental e do $1^{\circ}$ Relatório Parcial de Cumprimento do Convênio - apresentam-se objetivos que almejam o desenvolvimento da Formação de Educadores Ambientais pela perspectiva crítica da Educação Ambiental da Classe Trabalhadora frente às relações de poder emanadas da classe "não-trabalhadora" burguesa.
\end{abstract}

Palavras-Chave: Educação Ambiental; Formação de Educadores Ambientais; Formação de Gestores Ambientais; Políticas Públicas; Fronteira Marítima.

\section{Resumen}

Este artículo se efectúa como resultado parcial de investigación de maestría, a través del Programa de Postgrado en Educación Ambiental de la Universidad Federal de Rio Grande (FURG), buscando comprender que Formación de Educadores (as) Ambientales se desarrolla en el Convenio 069/2015 por la FURG junto al Ayuntamiento Municipal de Rio Grande en el contexto del Licenciamiento Ambiental. Para ello, vislumbramos este convenio como centralidad comprendiendo la relevancia para el venir a ser de la Educación Ambiental que debe contemplar Programas de Educación Ambiental, para entendimiento de la realidad social de la Clase Trabajadora en regiones Frontera Marítima, exigidos en los licenciamientos municipales por los (as) Gestores (a) (as), los cuales consideramos Educadores (as) Ambientales. En este sentido, la investigación se desarrolla por el referencial teórico histórico, dialéctico y materialista, conducido a través de un Enfoque Cualitativo (TRIVIÑOS, 1987), valiéndose del Análisis de Contenido (BARDIN, 1977) para sistematización e

\footnotetext{
${ }^{1}$ Mestrando do Programa de Pós-Graduação em Educação Ambiental na Universidade Federal do Rio Grande (FURG), Rio Grande; RS; Brasil; molina.quimica@gmail.com

${ }^{2}$ Doutoranda em Educação Ambiental pelo PPGEA - FURG; Rio Grande; RS; Brasil; Financiamento: Coordenação de Aperfeiçoamento de Pessoal de Nível Superior - CAPES; darlenescabrera@gmail.com

${ }^{3}$ Doutor em Educação pela UFRGS; Porto Alegre; RS; Brasil; lfminasi@gmail.com
} 
interpretación de las informaciones recogidas en la coyuntura material del " el fenómeno de la investigación. De esta forma, como resultados parciales de esa investigación - a partir del análisis de las Políticas Nacionales Medio Ambiente y Educación Ambiental y del $1^{\circ}$ Informe Parcial de Cumplimiento del Convenio - se presentan objetivos que anhelan el desarrollo de la Formación de Educadores Ambientales por la perspectiva crítica de la Educación Ambiental de la clase trabajadora frente a las relaciones de poder emanadas de la clase "no trabajadora" burguesa.

Palabras claves: Educación ambiental; Formación de Educadores Ambientales; Formación de Gestores Ambientales; Public Policy; Frontera Marítima.

\begin{abstract}
This article is effective as a partial result of master's research, through the Graduate Program in Environmental Education of the Federal University of Rio Grande (FURG), aiming to understand that Training of Environmental Educators develops in Agreement 069/2015 by FURG with the Municipal Government of Rio Grande in the context of Environmental Licensing. To this end, we envisage this agreement as a centrality, including the relevance to the coming to be of Environmental Education, which should include Environmental Education Programs, to understand the social reality of the Working Class in Maritime Frontier regions, required in municipal licensing by the Managers as), which we consider Environmental Educators. Thus, this research develops through the historical, dialectical and materialist theoretical reference, conducted through a Qualitative Approach (TRIVIÑOS, 1987), using Content Analysis (BARDIN, 1977) for systematization and interpretation of the information collected in the material conjuncture of the research phenomenon. Thus, as partial results of this research - based on the analysis of the National Policies on Environment and Environmental Education and the 1st Partial Report on Compliance with the Agreement - the objectives are presented which aim at the development of Environmental Educators Training through the critical perspective of Environmental Education of the Working Class against the relations of power emanating from the bourgeois "non-working class".
\end{abstract}

Keywords: Environmental education; Training of Environmental Educators; Training of Environmental Managers; Maritime Frontier.

\title{
1. Introdução
}

$\mathrm{O}$ atual artigo insurge como proposta para discutir os resultados parciais de nossa pesquisa de dissertação de mestrado, a qual almeja compreender como se desenvolve a Formação de Educadores (as) Ambientais inserida junto ao Licenciamento Ambiental, da Secretaria de Município do Meio Ambiente da Prefeitura Municipal do Rio Grande - SMMAPMRG, região de Fronteira Marítima. Tal Formação se dá por meio do Convênio $\mathrm{N}^{\mathrm{o}}$ 069/2015, contratado entre Prefeitura Municipal do Rio Grande e Universidade Federal do Rio Grande - FURG, sendo desenvolvido por essa última.

Para tanto, nesse estudo, almejamos compreender como se articula a Formação de Educadores(as) Ambientais, focados no âmbito do município, tendo como contexto a Crise Ambiental em que vivemos, a qual estamos compreendendo-a como uma Crise Estrutural do Capital (MÉSZÁROS, 2008). Contanto, caracterizada esta como uma crise do sistema capitalista em todos os sentidos, a qual se alastra por diferentes setores sociais e afeta principalmente as bases da sobrevivência humana - as relações com a natureza externa ao homem. 
Nessa conjuntura, nossa pesquisa, em processo de desenvolvimento, fundamenta-se em uma perspectiva histórica, dialética e materialista, a qual caracterizamos a partir de uma abordagem qualitativa (TRIVIÑOS, 1987). Logo, considerando o viés teórico que orienta esse estudo, elegemos como metodologia de análise das informações a Análise de Conteúdos (BARDIN, 1977).

Já, nossos estudos desenvolvidos até momento, no que tange as Políticas Públicas ambientais, desvelam algumas afirmações iniciais acerca de nosso fenômeno de pesquisa - as quais estamos considerando como parte dos resultados encontrados - sendo elas: a Política Nacional de Meio Ambiente enquanto instrumento jurídico legal balizador do Licenciamento Ambiental em âmbito nacional; a Política Nacional de Educação Ambiental fundante à Formação de Educadores (as) Ambientais nos órgãos licenciadores, rompendo os limites de tal formação ser pertencente somente aos espaços formais; e, a referência a uma perspectiva de Educação Ambiental para a Formação de Educadores (as) Ambientais em uma perspectiva crítica tanto no Código Estadual de Meio Ambiente do Rio Grande do Sul, como no Convênio 069/2015 entre Prefeitura e FURG - o qual é a centralidade desse estudo.

Dessa forma, organizamos esse trabalho em primeiro momento com uma introdução para apresentação da temática de estudo; em segundo momento trazemos o método de trabalho e a metodologia que orienta essa pesquisa. Por conseguinte, discorremos, em terceira instância, sobre os pressupostos teóricos do Licenciamento Ambiental no geral, bem como refletimos e articulamos sobre os nossos resultados parciais da pesquisa no âmbito do Licenciamento Ambiental local, a partir do Convênio 069/2015 do município do Rio Grande, importante região de Fronteira Marítima nacional. E, por fim, organizamos nossas considerações sobre o caminho da pesquisa percorrida até então.

\section{Do Caminho Metodológico}

Almejamos com essa pesquisa desvelar a realidade material concreta a partir da fundamentação materialista. De forma que, possamos compreender a realidade o mais próximo possível da totalidade, explicitando, analisando e explicando os fenômenos objetivos enquanto ligações e relações dinâmicas concretas.

Compreendemos que todos os fenômenos na natureza se dão de maneira articulada na objetividade do mundo, precedem a consciência e tem como seu princípio primordial a matéria. Para tanto, reafirmamos fundamentados no materialismo dialético que a realidade existe independentemente da consciência, assim analisamos o fenômeno na tentativa de 
apreender suas conexões internas, seu movimento, bem como seus intrínsecos conflitos, suas contradições, o fenômeno enquanto unidade dos contrários e totalidade (CHEPTULIN, 1982).

Consequentemente, ao concebermos a pesquisa em Educação Ambiental como forma de interpretar, compreender e interferir no mundo, visamos uma abordagem qualitativa de pesquisa (TRIVIÑOS, 1987), de forma que possamos compreender que Formação de Educadores (as) Ambientais está sendo preconizada pelo Convênio 069/2015, o qual foi organizado entre Prefeitura do Rio Grande e FURG. Tal convênio foi elencado como centralidade dessa pesquisa tendo em vista seu intencional de desenvolver um processo de Formação de Educadores (as) Ambientais no papel do Gestor Ambiental no contexto do Licenciamento, de competência da Unidade de Licenciamento e Fiscalização Ambiental da SMMA/PMRG, região de Fronteira Marítima.

Logo, corroborando com a perspectiva teórica e qualitativa dessa pesquisa, buscamos na Análise de Conteúdos (BARDIN, 1977) a metodologia de análise das informações. Por se tratar de uma metodologia que analisa materiais objetivos, documentos legais, escritas, entrevistas e gravações, possibilitando ao pesquisador fazer uso dos materiais sempre que necessário sem haver modificações no seu conteúdo.

Compreendemos a relevância dessa proposta de estudo ao passo que a Formação de Educadores (as) Ambientais é preconizada como subsídio ao desenvolvimento dos Programas de Educação Ambiental no Licenciamento. Sendo a Educação Ambiental condicionante dos Licenciamentos Ambientais, de competência do município do Rio Grande, interessante Fronteira Marítima onde exaltamos sua importância como trabalho social, a qual pode vir a contribuir para a não degradação exacerbada dos recursos da natureza natural, bem como à manutenção das comunidades que mantém sua sobrevivência a partir das instâncias primárias dos recursos da natureza.

Assim, organizamos esse estudo motivados pela práxis cotidiana de um dos pesquisadores dessa proposta, o qual envolveu-se com o tema estando na função de Superintendente de Licenciamento e Fiscalização Ambiental na Secretaria de Município do Meio Ambiente da Prefeitura Municipal do Rio Grande. Nesse espaço, dentre suas atividades, o pesquisador tomou ciência do Convênio 069/2015, firmado e desenvolvido entre a Prefeitura e a FURG, para implantar os Programas de Formação Continuada de Gestores(as) Ambientais, incluindo assim a Educação Ambiental no Licenciamento Ambiental de competência local, o qual objetiva desenvolver a Formação Continuada para servidores da SMMA, outros gestores públicos e consultores privados, formação essa que estamos considerando como Formação de Educadores (as) Ambientais. 


\section{Dos pressupostos teóricos}

Discorreremos, nesse momento, sobre nosso processo de pesquisa, articulado com os fundamentos teóricos epistemológicos que orientam nossa compreensão sobre a realidade. Assim, começaremos nossas análises junto à configuração do Licenciamento Ambiental a partir das Políticas Públicas Ambientais organizadas em nosso país.

Dentre o compêndio de regramentos que a sociedade sucumbe, destacamos na história das Políticas Públicas brasileiras, três grandes marcos sendo eles: a criação da Lei 6.938 de 31 de agosto de 1981, que dispõe sobre a Política Nacional de Meio Ambiente - PNMA (BRASIL, 1981); a Constituição Federal do Brasil, promulgado em 05 de outubro de 1988 (BRASIL, 1988); a Lei 9.795, de 27 de abril de 1999, que institui a Política Nacional de Educação Ambiental - PNEA (BRASIL, 1999). Discorreremos, inicialmente, por meio da Política Nacional do Meio Ambiente.

Para tanto, a PNMA apresenta como objetivos a preservação, a melhoria e a recuperação da qualidade ambiental propícia à vida, visando assegurar no país condições ao desenvolvimento socioeconômico, aos interesses da segurança nacional e à proteção da dignidade da vida humana. Ainda nessa lei, em seu Artigo $2^{\circ}$, destacamos como a importância do planejamento e fiscalização do uso dos recursos ambientais a proteção dos ecossistemas, com a preservação de áreas representativas, o controle e zoneamento das atividades potencial ou efetivamente poluidoras, delineadores dos projetos de Licenciamento Ambiental, e anuncia-se a Educação Ambiental a todos os níveis do ensino, inclusive a educação em instituições formais e não-formais, objetivando a capacitação para participação ativa na defesa do ambiente (BRASIL, 1981).

Nessa política, no seu Artigo $4^{\circ}$, inciso VII, observamos a institucionalização da premissa do poluidor-pagador - mais um tocante do Licenciamento Ambiental - onde surge a imposição a quem polui de recuperar e/ou indenizar os danos causados, conduzindo ao usuário a responsabilidade de contribuir pela utilização de recursos ambientais com fins econômicos. Já no artigo $5^{\circ}$, onde se delimitam as abrangências das ações, define-se que as diretrizes da Política Nacional do Meio Ambiente que estão formuladas em normas e planos destinados a orientar a ação dos Governos da União, dos Estados, do Distrito Federal, dos Territórios e dos Municípios, no que se relaciona com a preservação da qualidade ambiental e manutenção do equilíbrio ecológico (BRASIL, 1981).

Entretanto, o Licenciamento Ambiental, cuja responsabilidade regulatória é definida pelo Artigo $8^{\circ}$ dessa Lei, tem sua regulação pelo Conselho Nacional de Meio Ambiente 
(CONAMA), como um dos instrumentos de ação do Estado previsto no artigo $9^{\circ}$ na Política Nacional de Meio Ambiente (BRASIL, 1981). Compreendemos que esse é apenas um dos instrumentos dentre os quais o Estado dispõe para a realização da Gestão Ambiental, contudo consideramos que o Licenciamento Ambiental seja o principal mediador das relações do Estado com as empresas de interesse financeiro, caracterizando esse processo como de vital importância e responsabilidade do ordenamento e controle do uso dos recursos naturais, corroborando com o que compreendemos sobre a Gestão Ambiental do Estado, com fins no Licenciamento Ambiental, entendemos que:

o Estado brasileiro, ao praticar a gestão ambiental, está mediando disputas pelo acesso e uso dos recursos ambientais, em nome do interesse público, numa sociedade complexa, onde o conflito de interesses é inerente à sua existência. Nesse processo, ao decidir sobre a destinação dos bens ambientais (uso, não uso, como usa, quem usa, quando usa, para que usa, onde usa) o Poder Público, distribui custos e benefícios para a sociedade de modo desigual, no que diz respeito ao espaço e ao tempo, localização e duração dos empreendimentos (QUINTAS, 2005, p. 98).

Desse modo, concebemos que o Estado, ao permitir que a iniciativa privada e as instituições de Estado utilizem de forma desordenada determinado espaço e recursos da natureza, traz para si a responsabilidade dos impactos e os riscos decorrentes de determinado empreendimento. Entretanto, valendo-se do discurso de garantir o interesse coletivo, o Estado define condições para que qualquer empreendimento seja implementado, haja visto que os órgãos licenciadores e fiscalizadores são de competência pública e sofrem forte pressão política durante os processos de Licenciamento Ambiental, principalmente em região de Fronteira Marítima onde os interesses comerciais não são apenas locais, mas regionais.

Já a Constituição Federal do Brasil, em seu Artigo 23, apresenta como competência comum da União, dos estados e dos municípios, no inciso VII, proteger o meio ambiente e combater a poluição em todas as suas formas. Não obstante, a mesma no Artigo 225, define que todos têm o direito ao meio ambiente ecologicamente equilibrado e responsabilidade de proteger, preservar os territórios, a fauna e a flora (BRASIL, 1988). Compreendemos, de tal modo, que esses temas são suleadores ${ }^{4}$ dos processos de Licenciamento Ambiental desenvolvidos tanto pela esfera pública como privada.

Igualmente, no Artigo $225^{\circ}$ da Constituição brasileira, mais especificamente em seu inciso VI no $1^{\circ}$ parágrafo, prevê a obrigatoriedade da promoção da Educação Ambiental nos diferentes níveis e modalidades de ensino do país. Tal consideração impugna pela primeira

\footnotetext{
${ }^{4}$ Terminologia usada pelo jornalista uruguaio Eduardo Galeano para substituir o termo norteador, ratificando o posicionamento político que o ponto geográfico de partida ou de chegada também pode ser o sul.
} 
vez a afirmação do Poder Público brasileiro sobre a efetivação da dimensão da Educação Ambiental nos processos de ensino e aprendizagem no país.

Contanto, na Política Nacional de Educação Ambiental, identificamos a regulamentação da Educação Ambiental como o processo por meio do qual os indivíduos e a coletividade constroem valores sociais, conhecimentos, habilidades e competências voltadas para a conservação ambiental, sendo o meio ambiente um bem de uso comum, essencial a vida sadia. Assim, nesse documento, a Educação Ambiental é concebida como componente essencial da Educação nacional, estando presente, de forma articulada, em todos os níveis e modalidades do processo educativo, em caráter formal e não-formal (BRASIL, 1999).

A PNEA considera, no processo educativo mais amplo, promover a Educação Ambiental de maneira integrada aos programas educacionais que desenvolve, como ação dos órgãos vinculados ao Sistema Nacional de Meio Ambiente (Sisnama), sendo a Secretaria de Município do Meio Ambiente (SMMA) da Prefeitura Municipal do Rio Grande um dos integrantes desse sistema. Não obstante, consideramos importante exaltar o papel do Estado enquanto regulador do Licenciamento Ambiental das instituições privadas e públicas, na figura da SMMA, condicionando aos seus licenciados o desenvolvimento de Programas de Educação Ambiental destinados à capacitação dos trabalhadores, visando à melhoria e o controle efetivo sobre o ambiente de trabalho e sobre as repercussões do processo produtivo no ambiente como um todo.

Sendo assim, um dos principais espaços de garantir a efetivação da Educação Ambiental nos empreendimentos é o Licenciamento Ambiental, onde os Programas de Educação Ambiental se inserem como condicionante das licenças. Podemos dizer que no Licenciamento Ambiental existe um espaço de tensão entre interesses públicos e privados, o que torna esse [Licenciamento Ambiental] instrumento de grande relevância da Política Nacional de Meio Ambiente voltado para a participação e controle social.

A Educação Ambiental no Licenciamento Ambiental, assim, atua fundamentalmente na gestão dos conflitos de uso e impactos ocasionados por um empreendimento, objetivando garantir: a participação e a mobilização dos grupos afetados em todas as etapas do Licenciamento e nas instâncias públicas decisórias; a apropriação das informações pertinentes ao empreendimento pelo poder público; a produção de conhecimentos que permitam o posicionamento responsável e qualificado dos agentes sociais envolvidos. No Licenciamento Ambiental, a vertente da Educação Ambiental a ser desenvolvida é definida pelo órgão licenciador. 
Nesse sentido, consideramos a necessidade de compreender qual Educação Ambiental está sendo preconizada, pois segundo Layrargues (2011), no Brasil há diferentes macrotendências político-pedagógicas da Educação Ambiental contemporânea, as quais se apresentam, como: conservadora, pragmática e crítica. Assim, estamos compreendendo a partir desse autor que a tendência conservadora tem como princípios ecológicos: a valorização da dimensão afetiva em relação à natureza e a mudança dos comportamentos individuais em relação ao ambiente, não questionando a superestrutura social vigente em sua totalidade, mas apenas de partes ou setores sociais (LAYRARGUES, 2011).

Já, a tendência pragmática prima pelo desenvolvimento e consumo sustentável, nessa concepção o meio ambiente é destituído de componentes humanos, como uma mera coleção de recursos naturais em processo de esgotamento, aludindo-se então ao combate ao desperdício, mas há uma terceira vertente caracterizada pelo autor que se constitui em uma perspectiva crítica, a qual se define em oposição às tendências conservadoras e pragmáticas, buscando o enfrentamento político das desigualdades e das injustiças ambientais. Igualmente, essa vertente problematiza as contradições do modo de produção vigente e seu desenvolvimento econômico e político, introduzindo na sociedade o debate da cidadania, da democracia, da participação, da emancipação humana e da transformação social (LAYRARGUES, 2011).

Nesse sentido, compreendemos que os projetos de Educação Ambiental exigidos como condicionante de Licença devem atender as diretrizes da Educação Ambiental Crítica, no processo de gestão ambiental pública. Assim, possibilitando nos órgãos licenciadores projetos de Educação Ambiental para além da realização de ações pontuais, fragmentadas e despolitizadas, organizando projetos que permitam contextualizar os limites e possibilidades de renovação da natureza natural e de permanência das comunidades locais nos territórios de onde provem os recursos primários de suas atividades de trabalho. Logo, almejamos a Educação Ambiental no processo de Licenciamento Ambiental como controle social na elaboração e execução de Políticas Públicas em região de Fronteira Marítima, por meio da participação permanente dos cidadãos, principalmente de forma coletiva, na gestão do uso dos recursos ambientais e nas decisões que afetam a qualidade do meio ambiente (QUINTAS, 2005).

Ao assumirmos esse pressuposto, com base no pensamento de Quintas (2005), admitimos que a gestão ambiental não se esgota em suas dimensões administrativas e técnicas, mas é estruturada e permeada por relações políticas e econômicas que situam as próprias escolhas técnicas. Assim sendo, concebemos a Educação Ambiental no 
Licenciamento Ambiental como um processo de mediação entre os interesses dos sujeitos que vivem no território a ser licenciado e os empreendedores que visam o uso do local, esse processo de mediação define e redefine, continuamente, o modo como os diferentes sujeitos, por meio de suas práticas, alteram a qualidade do meio ambiente, e, também, como se distribuem os custos e os benefícios decorrentes da ação desses agentes.

\section{Da formação continuada}

Reafirmamos a necessidade da Educação Ambiental no cerne dos Licenciamentos Ambientais no município do Rio Grande enquanto perspectiva crítica. De modo que, consideramos a premência do trabalho local com a Educação Ambiental no Licenciamento conforme garante PNMA e a PNEA, bem como é direcionado pelo Código Estadual do Meio Ambiente do Rio Grande do Sul - Lei 11.520/2000 (BRASIL, 2000).

A Lei 11.520 (BRASIL, 2000) possibilita o desenvolvimento de Programas de Educação Ambiental como condicionante dos empreendimentos licenciáveis. Bem como, define que as penalidades de multas aplicadas a infratores, não reincidentes, poderão ser substituídas por Programas de Educação Ambiental destinados à área afetada pelas infrações ambientais, desde que haja aprovação desses Programas pelo órgão licenciador competente.

Não obstante, consideramos pertinente salientar que o município do Rio Grande faz uso dessas legislações para instituir, no seu rito de Licenciamento Ambiental, Programas de Educação Ambiental nas atividades por ele licenciáveis. Desse modo, o poder público municipal institucionaliza essas ações através da Secretaria de Município do Meio Ambiente (SMMA), conforme atividades definidas pela resolução 288/2014 do Conselho Estadual do Meio Ambiente (CONSEMA) e por convênio de ampliação de competência para Licenciamento, Fiscalização e Monitoramento Ambiental, constituindo assim as tipologias do Licenciamento Ambiental do município do Rio Grande, uma região de Fronteira Marítima de relevância nacional.

Ademais, a Prefeitura do Rio Grande, no ano de 2016, tem sua ação ampliada quanto ao Licenciamento Ambiental e quanto a complexidade da efetivação de Programas de Educação Ambiental como condicionante do Licenciamento. Dessa forma, mediante o município ter ampliado sua competência no que tange a regulação e expedição de Licenciamento Ambiental, consideramos de extrema relevância compreendermos que Formação de Educadores (as) Ambientais está sendo preconizada pela SMMA - PMRG, visto que haverá significativa ampliação do desenvolvimento de Programas de Educação Ambiental 
direcionados pelos Educadores Ambientais, os quais são servidores do municipais e são sujeitos de ensino-aprendizagem do Convênio 069/2015 da prefeitura.

Para tanto, estamos compreendendo a Formação de Educadores(as) Ambientais ancorados na teoria crítica, de forma que temos no Materialismo Histórico, desenvolvido por Marx (1996, 2003), uma das possibilidades de interpretação da realidade. A partir dessa teoria concebemos que nenhum processo social pode ser compreendido de forma isolada, como uma instância neutra e acima dos conflitos materiais e ideológicos da sociedade, sendo necessário compreender todos os fenômenos da realidade concreta de acordo com suas relações e contradições, que se estabelecem numa determinada materialidade histórica.

Assim, de acordo com essa perspectiva teórica compreendemos que o modelo econômico vigente tem como racionalidade a lucratividade em todas as cadeias de seu processo produtivo (COGGIOLA, 2004). Para tanto, a racionalidade capitalista de mercado não abre brechas em seus cálculos para a contraditória racionalidade ecológica, a qual considera a temporalidade dos ciclos naturais e a lenta possibilidade de restauração dos recursos da natureza.

Entendemos, portanto, que a Crise Ambiental atual está no modo de produção capitalista - o qual configura uma consciência social para manutenção da ordem de mercado estabelecida e não como pauta da redução do consumo, conforme dissemina a indústria. Subsidiados por essa concepção - que designa a Crise Ambiental como Crise Estrutural do Capital (MÉSZAROS, 2011) - conduzimos o fundamento desse estudo.

Logo, estamos compreendendo o trabalho como uma atividade vital à existência humana (LUKÁCS, 1981), enquanto atividade criativa que produz a sociedade e desenvolve a Educação (KONDER, 2008) consideramos de extrema relevância a intencionalidade do Licenciamento Ambiental e da Formação dos Educadores Ambientais pelo viés da Educação Ambiental Crítica:

entre a necessidade de transmissão de uma cultura existente (valores, ciência, ideologia), que é a tarefa conservadora da educação, e a necessidade de criação de uma nova cultura que é tarefa revolucionária da educação (GADOTTI, 1975, p. 61).

Assim, objetivamos que se efetive na realidade uma Educação Ambiental Crítica que tem em seu cerne a Formação de Educadores (as) Ambientais, os quais constituirão outra sociedade pautada em princípios de valorização a vida humana, pautados por uma práxis que implica ação e reflexão dos homens sobre o mundo para transformá-lo (FREIRE, 1987).

Consideramos, por conseguinte, o trabalho do Educador (a) Ambiental como uma das formas de superação desse modelo de sociedade, condicionada pelo modo de produção 
capitalista. Para tanto, afirmamos o desenvolvimento de uma Formação de Educadores (as) Ambientais conscientes de sua condição no mundo e dos processos do capital, consciência essa que não seja solitária, mas sim uma consciência de classe, em específico da classe trabalhadora.

\section{Das considerações finais}

Posterior a análise da fundamentação teórica, que alicerça esse estudo e a análise das informações parciais coletadas até então, trazemos como considerações finais desta pesquisa em desenvolvimento alguns resultados no âmbito da legislação, sobre o Licenciamento Ambiental, os quais versam sobre a instituição de Programas de Educação Ambiental sob a orientação de órgãos públicos que vão da esfera federal à municipal. Bem como contextualizam a Formação de Educadores(as) Ambientais na SMMA do Rio Grande (RS), região de Fronteira Marítima, centrada no convênio 069/2015 entre a Prefeitura e a FURG.

Em consequência, compreendemos que o Licenciamento Ambiental possui caráter vital para o desenvolvimento de políticas públicas, constituindo no âmago desse processo a Educação Ambiental. De tal forma que os Programas de Educação Ambiental exigidos como condicionante de Licenças atendam as diretrizes de uma Educação Ambiental Crítica, tornando-se parte do processo de gestão ambiental pública.

Assim, consideramos que a Educação Ambiental desenvolvida nos órgãos licenciadores em região de Fronteira Marítima tem a possibilidade de transformar essas estruturas habitualmente cartoriais, em espaços revolucionários. Com isso, trabalhando para além ações pontuais, fragmentadas e despolitizadas, organizando os Programas de Educação Ambiental contextualizados e provedores de possibilidades de renovação da natureza natural, onde historicamente se desenvolvem as comunidades locais.

A Educação Ambiental, conforme determina a PNEA, é um importante instrumento para minimizar os impactos ambientais na implementação de quaisquer empreendimentos que afetam o meio ambiente e a qualidade de vida das populações. Por tanto, compreendemos que a Educação Ambiental possibilita ao indivíduo, e à coletividade, perceberem-se como sujeitos sociais capazes de compreenderem a complexidade da relação sociedade-natureza, bem como de se comprometerem em agir em prol da prevenção de riscos e danos ambientais, causados por intervenções no ambiente físico natural e construído.

Desse modo, cabe a SMMA do Rio Grande, enquanto responsável pelos processos de Licenciamento Ambiental municipal, ter gestores ambientais capacitados à proposição de Programas de Educação Ambiental que possam sanar as reais necessidades sociais e 
ambientais do município do Rio Grande. Para tanto, compreendemos que, a formação a partir do Convênio 069/2015 para os gestores ambientais terá a possibilidade de desenvolvimento exitoso se for concebida como Formação de Educadores(as) Ambientais, em uma perspectiva crítica.

\section{Referências}

BARDIN, Laurence. Análise de Conteúdo. Lisboa/ Portugal: Edições 70. 1977

BRASIL ${ }^{1}$. Política Nacional de Meio Ambiente, de 31 de agosto de 1981. Disponível em:<http://www.sema.rs.gov.br/upload/Lei\%20Federal\%20n\%C2\%BA\%206938_1981.pdf>. Acesso em: 06/11/2016.

BRASIL ${ }^{2}$. Constituição da República Federativa do Brasil: promulgada em 5 de outubro de 1988. - atual até a Emenda Constitucional no 57, de 18/12/2008. - São Paulo: Editora Escala, 2009.

BRASIL ${ }^{3}$. Política Nacional de Educação Ambiental, de 27 de abril de 1999. Disponível em: <http://www.planalto.gov.br/ccivil_03/leis/19795.htm>. Acesso em: 06/11/2016

CHEPTULIN, A. A Dialética Materialista: categorias e leis da dialética. São Paulo: Alfaômega, 1982.

COGGIOLA, Osvaldo. Ecologia e Marxismo. Revista Motrivivência. Ano XVI, nº 22, p. 3946, Junho de 2004. Disponível em: https://periodicos.ufsc.br/index.php/motrivivencia/article/.../1183/1887>. Acesso em: 06/11/2016.

FREIRE, P. - Pedagogia do Oprimido, $17^{\circ}$ edição. Rio de Janeiro, Paz e Terra, 1987.

GADOTTI, M. Comunicação Docente: ensaio de caracterização da relação educadora, São Paulo: Edições Loyla, 1975.

KONDER, Leandro. Marxismo e Alienação. São Paulo: Expressão Popular, 2008.

LAYRARGUES, P. P. e LIMA, G. F. C. Mapeando as macro-tendências político ideológicas da educação Ambiental contemporânea no Brasil. In: Encontro "Pesquisa em Educação Ambiental", 2011, Ribeirão Preto. Anais do Encontro "Pesquisa em Educação Ambiental", 2011.

LUKÁCS, György. Ontologia dell'esseresociale. Roma: Riuniti, 1981. Tradução Sérgio Lessa, disponível em http://www.sergiolessa.com - acesso em 15/09/2012.

MARX, K. Manuscritos econômicos e filosóficos. São Paulo: Martin Claret, 2003.

MARX, K. Para a crítica da economia política. São Paulo, Ed. Nova Cultural, 1996.

MÉSZÁROS, Istvan. Educação para além do capital. $2^{\mathrm{a}}$ Ed. São Paulo: Boitempo, 2008. 
QUINTAS, J. S. Pensando e Praticando a Educação Ambiental no Processo de Gestão Ambiental: uma concepção pedagógica e metodológica para a prática da educação ambiental no licenciamento. Brasília: IBAMA, 2005.

TRIVIÑOS, Augusto Nibaldo Silva. Introdução à pesquisa em ciências sociais: a pesquisa qualitativa em educação. São Paulo: Atlas, 1987. 